\title{
Rentabilidade do milho e do feijão submetido a diferentes lâminas de irrigação em Mato Grosso
}

\author{
Profitability of maize and beans submitted to different \\ irrigation depths in Mato Grosso
}

\author{
Alice Medeiros Osti ${ }^{1}$ (D), Rivanildo Dallacort ${ }^{1}$ (D), Rafael Cesar Tieppo ${ }^{1}$ \\ Cleci Grzebieluckas ${ }^{1}$ (D) e Adelair Mendes Conceição ${ }^{1}$
}

\begin{abstract}
Resumo: Quantificar o consumo hídrico para a irrigação é essencial para otimizar o uso da água e contribuir para o alcance da eficiência econômica, que pode ser articulada com planejamento e estratégias de manejo. O objetivo desta pesquisa consiste em quantificar o custo variável do manejo da irrigação e a rentabilidade de milho e feijão aliados à economia do recurso hídrico no estado de Mato Grosso. Foram levantados os dados das lâminas de irrigação para as culturas do milho e o feijão, dos custos de produção e receitas com as vendas através de dados do Imea e da Conab para a safra 2015/2016. Os dados foram submetidos à Razão Benefício/Custo (B/C) para fins de análise da rentabilidade, e à análise da eficiência do uso da água. As lâminas de $190 \mathrm{~mm}$ para a irrigação do milho e de 522,17 mm para a irrigação do feijão são as melhores a serem aplicadas pelo produtor, visando equilíbrio econômico e ambiental, pois apresentaram maior eficiência no uso da água aliadas à maior taxa de rentabilidade frente às demais lâminas.
\end{abstract}

Palavras-chaves: consumo hídrico, receita líquida, irrigação.

Abstract: Quantifying water consumption for irrigation is essential to optimize water use and contribute to the achievement of economic efficiency, and can be articulated with planning and management strategies. The objective of this research is to quantify the variable cost of irrigation management and the yield of maize and beans along with the economy of water resource in Mato Grosso State, Brazil. Data were collected from the irrigation slides for maize and beans, from production costs and revenues from sales through Imea and Conab data referring to the 2015/2016 crop. Data were submitted to the Benefit / Cost Ratio (B / C) for profitability analysis purposes, and an analysis of efficiency water use. The $190 \mathrm{~mm}$ blade for maize irrigation and the

Data de submissão: 8 de outubro de 2017. Data de aceite: 7 de outubro de 2018.

1. Universidade do Estado de Mato Grosso (UNEMAT), Tangará da Serra (MT), Brasil.

E-mails: medeiros.dii@gmail.com; rivanildo@unemat.br; rafatieppo@gmail.com; cleci@unemat.br; adelairmendes@hotmail.com 
$522.17 \mathrm{~mm}$ blade for bean irrigation are the best slides to be applied by the producer, aiming economic and environmental balance, since they presented greater efficiency in the water use together with the higher rate of profitability compared to other slides.

Key-words: water consumption, net revenue, irrigation.

Classificação JEL: Q10.

\section{Introdução}

A água é um recurso natural extremamente importante para a sobrevivência; no entanto, está cada vez mais escasso devido ao uso inadequado, e tem sido tratado com displicência pelas entidades públicas e privadas. Além disso, com o crescente aumento da população, há a necessidade de aumentar a produção de alimento e o consumo de água, tanto para o sistema produtivo quanto para o consumo (Gomes et al., 2016).

O crescimento econômico e demográfico do Brasil nos últimos anos gerou aumento na utilização dos recursos hídricos, ultrapassando os limites tanto em quantidade como em qualidade e provocando problemas com gerenciamento da água (Victorino, 2007). Com escassez de água em muitos lugares, pelo uso desordenado e poluição, pesquisa-se a utilização de métodos para reduzir ou racionalizar o uso da água, energia elétrica e, consequentemente, dos custos e outros insumos utilizados na produção agrícola (Castiblanco, 2009).

Devido ao descontentamento com a gestão dos recursos hídricos, iniciaram-se pesquisas em diversos lugares sobre a pegada hídrica que relaciona o consumo de água pelas pessoas e produtos em diversas situações. O setor agrícola é um dos agentes que utilizam grande quantidade de água, portanto, torna-se necessária a economia dos recursos hídricos com planejamento do consumo de forma precisa em cada operação (Silva et al., 2013).

A eficiência do uso da água é uma alternativa para a otimização desse recurso, destarte torna-se necessária a redução do consumo que se refere à economia de água (Barros \& Amim, 2008), e requer estratégias de manejo para calcular a quantidade de água e melhorar os níveis de distribuição.

Os métodos e equipamentos de irrigação devem ser aperfeiçoados para reduzir as perdas e induzir ao manejo adequado, relacionando com o solo, a planta e o clima. Pequenas alterações na eficiência do uso da água podem torná-la disponível para outros fins e, quanto maior for a eficiência, menor serão os custos de bombeamento, condução e distribuição da água (Castro Júnior et al., 2015).

Em decorrência das pressões econômicas sobre os agricultores, ocorreram mudanças nas práticas da irrigação, pela crescente competição do uso da água e dos impactos ambientais da irrigação, motivadas pelo foco mais na eficiência econômica do que na demanda de água da cultura (Frizzone, 2007).

Técnicas de manejo da água são indispensáveis para potencializar a produção das culturas e, principalmente, para realizar aplicação eficiente da água, fundamental nos dias atuais devido à escassez dos recursos hídricos e, com isso, deve-se dar maior atenção ao planejamento da agricultura irrigada por ser um dos setores que demandam maiores volumes de água (Cunha et al., 2013).

A lâmina total de água necessária para cada cultura também deve atender às exigências hídricas das plantas em todo seu ciclo de desenvolvimento, que varia de um período para outro, pela maior evapotranspiração (Köpp et al., 2015). 
Desta forma, é imprescindível controlar as lâminas de irrigação, pois, em excesso, pode causar perda de água por escoamento superficial, erosão do solo, lixiviação e, consequentemente, desperdício de energia, elevando o custo operacional (Pegorare et al., 2009).

Um dos grandes desafios dos produtores rurais é aumentar sua produtividade aliando à redução dos custos, para obter maiores rentabilidade e lucratividade. Diante disso, manejar a irrigação torna-se um diferencial competitivo para obter maior produtividade em locais menos chuvosos (Vescove, 2010).

Para auxiliar nas tomadas de decisão é preciso realizar uma análise da rentabilidade financeira, pois se espera que os projetos de irrigação sejam lucrativos, de forma a obter maior retorno que os valores gastos com insumos (Costa, 2006).

Aliar o lucro com a economia da água na irrigação é algo complexo e desafiador, visto que, diante do fator econômico, uma irrigação ótima implica em menores lâminas aplicadas, o que pode causar a redução da produtividade da cultura. No entanto, esta poderá trazer algumas vantagens significativas, como: aumento da eficiência da irrigação, redução dos custos da irrigação e redução dos riscos associados aos impactos ambientais decorrentes da irrigação (Castro Júnior et al., 2015).

O sistema de cobrança pela utilização da água na irrigação é uma medida que busca, de certa forma, promover o uso sustentável dos recursos hídricos, em que o irrigante passa a controlar seu consumo, podendo aumentar a qualidade e a quantidade de água disponível (Beyruth, 2008).

Essa pesquisa teve como objetivo quantificar o custo variável do manejo da irrigação e a rentabilidade de milho e feijão aliados à economia do recurso hídrico no estado de Mato Grosso.

Devido à importância dos produtores ao uso de novas tecnologias e à preocupação ambiental decorrente das mudanças climáticas, dentre outros, esta pesquisa poderá auxiliar o produtor a decidir qual lâmina de irrigação deverá aplicar com base na rentabilidade aliados à economia do uso da água.

\section{Material e métodos}

A pesquisa foi desenvolvida no Laboratório de Meteorologia, nas dependências da Universidade do Estado de Mato Grosso (Unemat), campus de Tangará da
Serra - MT, situada geograficamente na latitude $14^{\circ} 39^{\prime}$ S; longitude $57^{\circ} 25^{\prime} \mathrm{W}$, a 440 metros de altitude.

Na primeira etapa do trabalho foram levantados dados referentes às lâminas de irrigação, tempo utilizado para irrigar e a produtividade das culturas do milho e do feijão a partir de revisão bibliográfica, em que os dados referentes à cultura do milho de segunda safra foram adquiridos a partir de Pegorare et al. (2009), e os dados do feijão foram obtidos a partir de Fenner (2015).

A segunda etapa consistiu em submeter os dados de lâminas de irrigação e as respectivas produtividades das culturas a uma quantificação, ou seja, aos cálculos de custos variáveis, receitas e indicador de rentabilidade para avaliar o retorno econômico de cada lâmina. Em seguida foi realizado cálculo de eficiência do uso da água como um indicador de consumo hídrico e quantidade de grãos produzidos $(\mathrm{kg} / \mathrm{mm})$.

O trabalho de Pegorare et al. (2009) foi desenvolvido no campus de Dourados (MS), com a cultura do milho de segunda safra híbrido triplo de ciclo precoce DG-501, no período de março a setembro, num Latossolo Vermelho Distroférrico, sendo este um dos tipos de solo que também existe na região de Tangará da Serra (MT).

Foram considerados dados de quatro lâminas de irrigação suplementar, de acordo com a evapotranspiração de referência (ETo) baseada na metodologia de Penman-Monteith (Food and Agriculture Organization - FAO 56), que gerou as produtividades (Tabela 1). A irrigação foi estimada para suprir as perdas de evapotranspiração da cultura, em que a irrigação total incluiu a irrigação suplementar somada à precipitação em cada tratamento.

As chuvas apresentaram total de $220 \mathrm{~mm}$ em todo o ciclo da cultura do milho. O sistema de irrigação utilizado foi por aspersão convencional, com espaçamento 12/12 metros entre linhas e na linha, e lâmina média diária de $5,3 \mathrm{~mm}$.

Para realizar o cálculo financeiro das lâminas de água foram utilizados dados de custos totais de produção e os benefícios com o preço médio de comercialização das culturas, com base na fonte de dados da Conab (Companhia Nacional do Abastecimento) e do Imea (Instituto Mato-Grossense de Economia Agropecuária).

De acordo o Imea, para a safra 2015/2016, o preço médio de comercialização do milho de segunda safra foi de $\mathrm{R} \$ 29,35$ por saca de $60 \mathrm{~kg}$, em Campo Verde (MT).

Já o custo total da produção, sem considerar a irrigação, para o estado de Mato Grosso, foi de R\$2.566,33/ ha ${ }^{-1}$ 
(Instituto Mato-Grossense de Economia Agropecuária, 2016). Neste total também foram inseridos os custos variáveis com mão de obra e manutenção do equipamento de irrigação.

A cultura do feijão e os dados das respectivas lâminas utilizadas na irrigação e na produtividade foram obtidos de acordo com o trabalho de Fenner (2015), que realizou experimento com cultivar a BRS Estilo do feijão.

A pesquisa de Fenner (2015) foi desenvolvida na Unemat campus de Tangará da Serra (MT) e utilizou dados de uma estação do Instituto Nacional de Meteorologia (Inmet) localizada próxima à área experimental, para a estimativa da ETo Penman-Monteith - FAO. O delineamento foi o de blocos ao acaso, com esquema fatorial $4 \times 5 \mathrm{com}$ 4 repetições. $\mathrm{O}$ experimento a campo foi realizado a partir de 11/07/2014 e a colheita, no dia 30/09/2014.

Cada parcela foi constituída por seis linhas espaçadas em 0,45 m, com 6,00 m de comprimento, com uma semeadora para plantio direto.

O manejo da irrigação foi realizado a partir de um sistema por aspersão com coeficiente de uniformidade de $82 \%$ e lâmina média diária de $7 \mathrm{~mm}$ com pressão de 30 m.c.a., sendo que cada bloco representou uma lâmina de irrigação, composto por um total de seis aspersores cada.

Também foram definidas quatro lâminas de irrigação suplementar de acordo com a ETo de 30, 70, 110 e 150\%, destacando-se que não houve precipitação na época da semeadura e desenvolvimento da planta (Tabela 2).
O preço médio de comercialização do feijão foi de R\$ 196,00/saca de $60 \mathrm{~kg}$. Este preço é uma média dos valores praticados entre dezembro de 2016 e janeiro de 2017 no Paraná, em Goiás, na Bahia, em São Paulo e Santa Catarina, os maiores estados produtores do Brasil. $\mathrm{O}$ custo de produção do feijão foi de R\$3.586,51/ ha-1 (Companhia Nacional de Abastecimento, 2017).

A partir dos dados levantados referentes à produtividade do milho de segunda safra e feijão, foram calculadas as receitas e os custos de produção. Nesta pesquisa multiplicou-se o valor das vendas pelas sacas dos grãos para obter a receita.

Os custos da produção, como preparo do solo, plantio, tratos culturais, colheita, entre outros, foram mantidos fixos para todos os tratamentos, a fim de analisar a influência do custo variável da irrigação em cada lâmina.

Para a realização dos cálculos foi considerado que o sistema de irrigação já estivesse em funcionamento no campo, para avaliar apenas o custo variável da lâmina de água, pois o aumento ou a redução do volume da água aplicado não influencia no custo do investimento inicial com o projeto de irrigação ou vice-versa.

A partir dos dados das lâminas de água necessárias para irrigação, foram calculados os custos com a energia elétrica utilizada para bombeamento e a simulação do custo pelo uso da água para analisar a rentabilidade das lâminas de irrigação. Os cálculos de custos das lâminas de irrigação foram realizados no programa Excel (versão 2010), da Microsoft.

Tabela 1. Precipitação, lâminas de irrigação e produtividade do milho

\begin{tabular}{lcccc}
\hline & Lâmina 1 & Lâmina 2 & Lâmina 3 & Lâmina 4 \\
\hline Precipitação & 220 & 220 & 220 & 220 \\
Lâminas (mm) & 140 & 190 & 290 & 388 \\
Lâmina total aplicada & 360 & 410 & 510 & 608 \\
Produtividade (kg ha-1) & 5.642 & 6.380 & 6.842 & 6.972 \\
\hline
\end{tabular}

Fonte: Elaborado pela autora.

Tabela 2. Precipitação, lâminas de irrigação e produtividade do feijão

\begin{tabular}{lcccc} 
& Lâmina 1 & Lâmina 2 & Lâmina 3 & Lâmina 4 \\
\hline Precipitação & 0 & 0 & 0 & 0 \\
Lâminas (mm) & 295,14 & 408,65 & 522,17 & 635,69 \\
Lâmina total aplicada & 295,14 & 408,65 & 522,17 & 635,69 \\
Produtividade (kg ha ${ }^{-1}$ ) & 588 & $1.556,11$ & $2.246,30$ & $2.377,68$ \\
\hline
\end{tabular}

Fonte: Elaborado pela autora. 
O custo com consumo da água foi calculado de acordo com o Sistema Digital de Cobrança (Digicob) (Figura 1) aplicado à bacia do Rio Doce de Minas Gerais, para valorar o preço da água, visto que atualmente ainda não há cobrança pelo uso da água para irrigação em Mato Grosso.

Neste sistema, a cobrança foi definida pela multiplicação entre a base de cálculo do volume de água captado (Vcap) pelo preço unitário da captação $(\mathrm{Pu}=0,035)$, pelo coeficiente que enquadra o corpo d'água onde se faz a captação $($ Kcap $=1)$, bem como o coeficiente que leva em conta a natureza do uso, que neste caso, o valor obtido $(K=0,05)$ se enquadra em boas práticas de uso. A equação 1 a seguir apresenta a estrutura da cobrança:

$\mathrm{Cob}=\mathrm{Vcap} . \mathrm{Pu} . \mathrm{Cf}$

Em que:

$\mathrm{Cob}=$ cobrança $(\mathrm{R} \$)$;

Vcap = volume captado $\left(\mathrm{m}^{3}\right)$;

$\mathrm{Pu}=$ preço unitário $(\mathrm{R} \$)$;

$\mathrm{Cf}=$ Coeficientes $($ Kcap $\times \mathrm{K})$.

De acordo com dados da Agência Nacional de Águas (Agência Nacional de Águas, 2016) em Mato Grosso, o tamanho médio das áreas irrigadas nas propriedades agrícolas é de 120 hectares, em média, com 67.071 hectares de áreas irrigadas por pivô central e uma média de 553 pivôs. Por isso, esta pesquisa se baseou neste tamanho de área para a realização dos cálculos econômicos.

O preço da energia elétrica, necessária para o funcionamento da motobomba, foi obtido através da empresa concessionária de energia elétrica de Mato Grosso, Energisa, definindo que a modalidade tarifária para produtores rurais, que utilizam a energia para irrigação, é a convencional de alta tensão para utilização de motores elétricos, classificada como rural, sendo o preço por consumo $\mathrm{R} \$ 0,36 / \mathrm{kWh}$. Os valores do PIS e Cofins sobre o consumo da energia foram de $0,97 \%$ e $4,46 \%$, respectivamente, e o ICMS, de $27 \%$, se ultrapassar $50 \mathrm{kWh}$ por mês.

Para realizar o cálculo de consumo de energia elétrica para irrigação baseou-se na potência da motobomba de $250 \mathrm{cv}$, ou seja, $184 \mathrm{~kW}$, vazão de $419 \mathrm{~m}^{3} \mathrm{~h}^{-1}$, capaz de irrigar uma área de 120 hectares (Oliveira \& Zocoler, 2013). Assumiu-se que a lâmina diária para irrigação do milho foi de 5,3 $\mathrm{mm}$ e, do feijão, de $7 \mathrm{~mm}$.

A partir da quantidade total de água por lâmina, a próxima etapa para calcular o custo com energia elétrica consumida foi identificar o tempo utilizado para a irrigação, que seguiu, de forma adaptada, o modelo de Oliveira et al. (2004), (equation 2):

Figura 1. Simulador de cobrança DIGICOB.

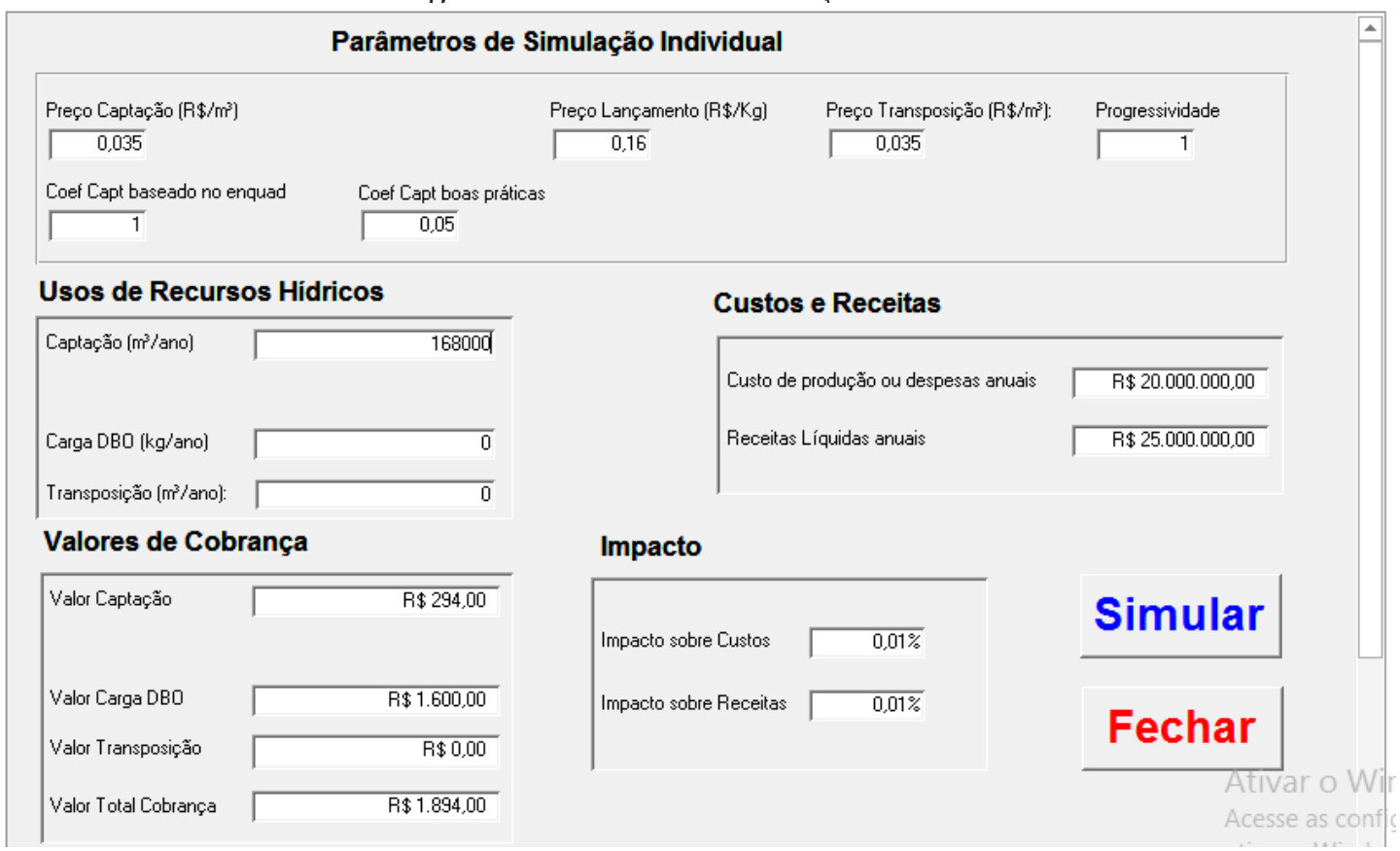

Fonte: ANA, 2010. 
$\mathrm{Ti}=\frac{\mathrm{LDA} \cdot 10 \cdot \mathrm{A}}{\mathrm{Qs}}$

Em que:

Ti = tempo de irrigação $(\mathrm{h})$;

LDA = lâmina diária aplicada $(\mathrm{mm})$;

$\mathrm{A}$ = área irrigada pelo pivô (ha);

Qs = vazão do pivô $\left(\mathrm{m}^{3} \mathrm{~h}-{ }^{1}\right)$.

Para identificar o total de dias com irrigação, foi realizada a divisão do total da lâmina aplicada em todo o ciclo da cultura pela lâmina diária. Exemplo: $140 \mathrm{~mm}$ $\div 5,3 \mathrm{~mm}=+$ ou- 26 dias. Para encontrar o total de horas de irrigação (Tempo de irrigação - Ti) foi multiplicado o total de dias com irrigação pelas horas diárias.

Em seguida calculou-se o custo da energia (CE), seguindo o modelo de Pegorare et al. (2009) com adaptações (equation 3):

$\mathrm{CE}=\mathrm{T} i \cdot \mathrm{Pm} \cdot \mathrm{P}+\mathrm{I}$

Em que:

$\mathrm{CE}=$ custo da energia elétrica $(\mathrm{R} \$)$;

$\mathrm{Ti}$ = tempo de irrigação (horas);

$\mathrm{Pm}=$ potência do motor $\left(184 \mathrm{~kW} \mathrm{~h}^{-1}\right)$;

$\mathrm{P}=$ preço do $\mathrm{Kw}(\mathrm{R} \$)$;

$\mathrm{I}$ = impostos (PIS, COFINS e ICMS).

Após a quantificação dos custos variáveis das lâminas de irrigação (custo da energia elétrica + custo da água), esses valores foram somados com os demais custos de produção. As receitas foram obtidas através dos valores de produtividade multiplicadas pelo valor de vendas pago ao produtor.

Os valores de receitas e custos foram submetidos ao indicador de rentabilidade chamado Razão Benefício/Custo (B / C) para indicar qual lâmina é capaz de trazer maior retorno econômico, que foi calculado com base no modelo de Castro Júnior et al. (2015), popularmente conhecido como "custo-benefício", pois este indicador é calculado para verificar se os benefícios são maiores que os custos (equation 4):

$\mathrm{R}_{\mathrm{b} / \mathrm{c}}=\frac{\sum_{\mathrm{t}=0}^{\mathrm{n}} \text { Receita }_{\mathrm{t}} \bullet(1+\mathrm{i})^{\mathrm{t}}}{\sum_{\mathrm{t}=0}^{\mathrm{n}} \text { Custo }_{\mathrm{t}} \bullet(1+\mathrm{t})}$

Em que:

$\mathrm{R}_{\mathrm{b} / \mathrm{c}}$ - Razão Benefício / Custo;

$\mathrm{B}$ - receitas totais em $\mathrm{R} \$$ ha $^{-1} ; \mathrm{C}$ - custos totais em $\mathrm{R} \$ \mathrm{ha}^{-1}$.

Porém, o objetivo desta pesquisa não está voltado apenas para o fator econômico, mas também aliar esse fator à questão ambiental com uso eficiente e econômico dos recursos hídricos e, para isso, foi realizada uma análise da eficiência do uso da água para aliar a lucratividade (equation 5) que seguiu o modelo cálculo de Cunha et al. (2013).

$\mathrm{EUA}=\frac{\mathrm{P}}{\text { LTA }}$

Em que:

EUA = eficiência do uso da água;

$\mathrm{P}=$ produtividade total de grãos por ha-1;

LTA = lâmina total aplicada por irrigação e precipitação pluvial.

\section{Resultados e discussão}

Nas lâminas de água da irrigação do milho de segunda safra houve aumento de $50 \mathrm{~mm}$ entre a segunda lâmina em relação à primeira, diferença de $35,71 \%$, explicada pela taxa de aplicação da água, que pode diferir conforme variabilidade espacial da disponibilidade hídrica do solo, de acordo com o manejo. Já na terceira lâmina houve aumento de $100 \mathrm{~mm}$ com relação à segunda, sendo $52,73 \%$ maior, e na quarta e última lâmina, houve aumento 33,79\% com relação à anterior, ou seja, o volume de água aplicado pelas lâminas não aumentou proporcionalmente.

Corroborando com Soares et al. (2012), a taxa de aplicação da água também diferiu quanto à disponibilidade hídrica do solo nos espaços, pois, na primeira lâmina, foi de 32,04 mm e apresentou variação de $40 \%$ na produção do milho em relação à maior lâmina, com disponibilidade hídrica de 78,13 $\mathrm{mm}$, havendo necessidade de maior aplicação de água.

O método proposto por Lotidi \& Mavropoulos (2018) para calcular a probabilidade da necessidade de irrigação por demanda pela média do tempo estimado, a fim de gerenciar a quantidade de água para a irrigação no nível da unidade, também apresenta concordância com esta pesquisa, em que o cálculo demonstra uma variabilidade no volume de água aplicado nos diferentes intervalos de irrigação, e o período de pico da irrigação serve como base de dados para auxiliar na gestão econômica.

O consumo energético por hectares foi de: lâmina de $140 \mathrm{~mm}=614,79 \mathrm{~kW}$, lâmina de $190 \mathrm{~mm}$ : 834,36 kW; lâmina de $290 \mathrm{~mm}$ : 1.273,5 kW; lâmina de $388 \mathrm{~mm}$ : 
1703,86 kW. O custo da energia elétrica para a irrigação do milho segunda safra está inserido na Tabela 3.

Pegorare et al. (2009) encontrou resultados inferiores com relação aos custos de energia elétrica por hectare. Para a região de Dourados (MS), foram: lâmina $1=\mathrm{R} \$ 26,25$; lâmina $2=\mathrm{R} \$ 43,75$; lâmina $3=\mathrm{R} \$ 78,75$ e lâmina $4=R \$ 113,05$, que pode estar relacionado ao valor da tarifa de cobrança anual pelo uso da energia nos estados, pois houve reajustes nos valores cobrados nos últimos oito anos.

O tempo utilizado para efetuar a operação de irrigação foi de 15,18 horas com aplicação de uma lâmina média de $5,3 \mathrm{~mm}$, sendo um valor aproximado ao resultado encontrado por Oliveira et al. (2004) com $5 \mathrm{~mm}$ de lâmina bruta na cultura do milho: em 120 ha, 14,30 horas diárias foram utilizadas, explicado pela uniformidade de aplicação da água e eficiência do potencial de aplicação da lâmina.

No estado de Mato Grosso, a tarifa de consumo de água para a irrigação ainda não é cobrada e nem fiscalizada, assim o produtor deve controlar o consumo por conta própria como forma de ação para o equilíbrio ambiental. $\mathrm{O}$ volume total de água $\left(\mathrm{m}^{3}\right)$ aplicado na cultura do milho, na área de 120 ha, foi: lâmina $1=168.000$; lâmina $2=228.000$; lâmina 3=348.000; e lâmina $4=465.600$.

Em relação aos custos com captação da água do milho safrinha, o maior custo foi gerado também pela lâmina de $388 \mathrm{~mm}$ com $\mathrm{R} \$ 6,79 \mathrm{ha}^{-1}$, e o menor, pela lâmina de $140 \mathrm{~mm}$ com custo de $\mathrm{R} \$ 2,45 \mathrm{ha}^{-1}$, aumento de $177,14 \%$ (Tabela 4).

O volume de água aplicado pela irrigação influenciou positivamente na produtividade do milho safrinha, de maneira que, ao elevar o volume da água, houve aumento da produtividade (Tabela 5).

Melhorias no rendimento e na produtividade de grãos também foram evidenciados na pesquisa de Thakur et al. (2018), através da modificação de práticas de cultivo e manejo da água, em que aplicou diferentes tratamentos de manejo de água durante, antes e depois do período vegetativo. Além disso, ocorreram diferentes respostas

Tabela 3. Custo da energia elétrica para irrigação do milho

\begin{tabular}{lrrrr}
\hline \multicolumn{1}{c}{ Lâminas aplicadas $(\mathbf{m m})$} & $\mathbf{1 4 0}$ & $\mathbf{1 9 0}$ & $\mathbf{2 9 0}$ & $\mathbf{3 8 8}$ \\
\hline Lâmina média diária & 5,30 & 5,30 & 5,30 & 5,30 \\
Dias de irrigação & 26,42 & 35,85 & 54,72 & 73,21 \\
Horas diárias irrigação & 15,18 & 15,18 & 15,18 & 15,18 \\
Horas totais & 400,95 & 544,15 & 830,55 & $1.111,22$ \\
Potência motor kW h ${ }^{-1}(250 \mathrm{cv})$ & 184,00 & 184,00 & 184,00 & 184,00 \\
Consumo de energia total (kW) & $73.775,66$ & $100.124,11$ & $152.821,00$ & $204.463,96$ \\
Preço kW h-1 (R\$) & 0,36 & 0,36 & 0,36 & 0,36 \\
Valor total (R\$) & $26.559,24$ & $36.044,68$ & $55.015,56$ & $73.607,03$ \\
Impostos (32,43\%) & $8.613,16$ & $11.689,29$ & $17.841,55$ & $23.870,76$ \\
Custo total em 120ha (R\$) & $35.172,40$ & $47.733,97$ & $72.857,11$ & $97.477,78$ \\
Custo da energia (ha) & $\mathbf{2 9 3 , 1 0}$ & $\mathbf{3 9 7 , 7 8}$ & $\mathbf{6 0 7 , 1 4}$ & $\mathbf{8 1 2 , 3 1}$ \\
\hline
\end{tabular}

Fonte: Elaborado pela autora.

Tabela 4. Custo com captação de água do milho

\begin{tabular}{lcccc}
\hline \multicolumn{1}{c}{ Lâmina total aplicada $(\mathbf{m m})$} & $\mathbf{1 4 0}$ & $\mathbf{1 9 0}$ & $\mathbf{2 9 0}$ & $\mathbf{3 8 8}$ \\
\hline Vazão do sistema $\left(\mathrm{m}^{3} \mathrm{~h}^{1}\right)$ & 419,9 & 419,9 & 419,9 & 419,9 \\
Horas irrigação em 120ha & 400 & 543 & 829 & 1109 \\
Volume de água total $\left(\mathrm{m}^{3}\right)$ & 168000 & 228000 & 348000 & 465600 \\
Preço unitário da água $\left(\mathrm{R} \$ \mathrm{~m}^{3}\right)$ & 0,035 & 0,035 & 0,035 & 0,035 \\
Coeficientes (Kcap X k) & 0,05 & 0,05 & 0,05 & 0,05 \\
Custo total água - 120 ha (R\$) & 294,00 & 399,00 & 609,00 & 814,80 \\
Custo da água ha (R\$) & $\mathbf{2 , 4 5}$ & $\mathbf{3 , 3 3}$ & $\mathbf{5 , 0 8}$ & $\mathbf{6 , 7 9}$ \\
\hline
\end{tabular}

Fonte: Elaborado pela autora. 
Tabela 5. Índice de rentabilidade razão benefício/custo e análise vertical (AV) e horizontal (AH) da irrigação do milho

\begin{tabular}{|c|c|c|c|c|c|c|c|c|c|c|c|}
\hline L & $140 \mathrm{~mm}$ & $\mathrm{AV}(\%)$ & $190 \mathrm{~mm}$ & $\operatorname{AV}(\%)$ & AH (\%) & $290 \mathrm{~mm}$ & $\operatorname{AV}(\%)$ & $\mathrm{AH}(\%)$ & $388 \mathrm{~mm}$ & $\operatorname{AV}(\%)$ & $\mathrm{AH}(\%)$ \\
\hline P & 5.642 & & 6.380 & & 13,1 & 6.842 & & 7,2 & 6.975 & & 1,9 \\
\hline SC & 94 & & 106 & & 13,1 & 114 & & 7,2 & 116 & & 1,9 \\
\hline RT & $2.759,88$ & 100,0 & $3.120,88$ & 100,0 & 13,1 & $3.346,88$ & 100,0 & 7,2 & $3.411,94$ & 100,0 & 1,9 \\
\hline $\mathrm{CP}$ & $2.566,33$ & 93,0 & $2.566,33$ & 82,2 & 0,0 & $2.566,33$ & 76,7 & 0,0 & $2.566,33$ & 75,2 & 0,0 \\
\hline CLA & 295,55 & 10,7 & 401,11 & 12,9 & 35,7 & 612,22 & 18,3 & 52,6 & 819,10 & 24,0 & 33,8 \\
\hline CT & $2.861,88$ & 103,7 & $2.967,44$ & 95,1 & 3,7 & $3.178,55$ & 95,0 & 7,1 & $3.385,43$ & 99,2 & 6,5 \\
\hline RL & $-102,00$ & $-3,7$ & 153,45 & 4,9 & 250,4 & 168,33 & 5,0 & 9,7 & 26,50 & 0,8 & $-84,3$ \\
\hline $\mathrm{B} / \mathrm{C}$ & 0,96 & & 1,05 & & & 1,05 & & & 1,01 & & \\
\hline
\end{tabular}

${ }^{*}$ L: lâmina; P: produtividade $\left(\mathrm{kg} \mathrm{ha}^{-1}\right)$; SC: sacas de $60 \mathrm{~kg}$; RT: receita total ( $\left(\mathrm{R}\right.$ ha-1); $\mathrm{CP}$ : custo de produção $\left(\mathrm{R} \$\right.$ ha $\left.{ }^{-1}\right)$; $\mathrm{CLA}$ : custo de lâmina de irrigação $\left(\mathrm{R} \$ \mathrm{ha}^{-1}\right) ; \mathrm{CT}$ : custo total $\left(\mathrm{R} \$ \mathrm{ha}^{-1}\right) ; \mathrm{RL}$ : receita líquida $\left(\mathrm{R} \$ \mathrm{ha}^{-1}\right) ; \mathrm{B} / \mathrm{C}$ : benefício/custo $(\%)$. Fonte: Elaborado pela autora.

das plantas diante das práticas de manejo modificadas e horários alternativos de irrigação, indicando que o desempenho fenotípico e fisiológico pode ser melhorado para um determinado genótipo.

Corroborando com a pesquisa de Martins et al. (2016), as produtividades do milho também aumentaram de acordo com a elevação do volume de água para cada lâmina de irrigação.

Ruviaro et al. (2011) basearam-se em valores acumulados de 20, 40 e $60 \mathrm{~mm}$ e observaram que a lâmina de $30 \mathrm{~mm}$ apresentou maior produtividade do grão, ou seja, neste caso não foi a maior lâmina de água que proporcionou aumento na produtividade.

O menor custo com a lâmina de irrigação foi gerado pela lâmina de $140 \mathrm{~mm}$ com total de R $\$ 295,55$ por hectare. Este valor é superior ao encontrado pelo Centro de Estudos Avançados em Economia Aplicada (2013), em que o custo com a irrigação por pivô central do milho safra 2013/14 na região de Cruz Alta (RS) foi de R\$134,43 por hectare; porém, deve-se considerar que este valor foi identificado há quatro anos, ou seja, a tendência com o passar dos anos é que os valores aumentem.

Uma pesquisa sobre viabilidade econômica da irrigação deficitária em milho irrigado foi aplicada às seguintes lâminas: lâmina 1= 113 mm; lâmina 2= 218 mm; lâmina 3= 316 mm; lâmina $4=389 \mathrm{~mm}$, e o custo variável com a irrigação (água + energia): lâmina $1=\mathrm{R} \$ 32,60$; lâmina $2=\mathrm{R} \$$ 63,00; lâmina $3=\mathrm{R} \$$ 91,30; e lâmina $4=\mathrm{R} \$ 112,30$ (Martins et al., 2016). Os menores custos variáveis da irrigação em relação à presente pesquisa foram obtidas nas menores laminas. Este fato pode estar relacionado às tarifas de energia elétrica, que são diferenciadas de um estado para outro, e pelo volume de água aplicado.
Para produzir cada saca de milho por hectare, as lâminas de água tiveram custos de: lâmina $140 \mathrm{~mm}=\mathrm{R} \$ 3,14$; lâmina $190 \mathrm{~mm}=\mathrm{R} \$$ 3,78; lâmina $290 \mathrm{~mm}=\mathrm{R} \$$ 5,37; lâmina $388 \mathrm{~mm}=\mathrm{R} \$ 7,06$ por hectare, com energia elétrica e consumo de água para cada saca.

A análise horizontal serve como base para observar as taxas de crescimento ou redução entre diversos fatores. Nesta pesquisa houve aumento dos custos entre as lâminas de irrigação. A lâmina de $290 \mathrm{~mm}$ gerou maior aumento no custo, de 52,6\%, com relação à lâmina de $190 \mathrm{~mm}$, superando as demais.

A maior taxa de crescimento da receita líquida entre as lâminas foi proporcionada pela lâmina de $190 \mathrm{~mm}$, com 250,4\% superior à lâmina de $140 \mathrm{~mm}$ que, por sua vez, apresentou custos totais superiores às receitas de vendas, gerando prejuízo.

As participações do custo da irrigação com relação aos custos totais representaram: lâmina $140 \mathrm{~mm}=10,32 \%$; lâmina $190 \mathrm{~mm}=13,51 \%$; lâmina $290 \mathrm{~mm}=19,26 \%$; e lâmina $388 \mathrm{~mm}=24,19 \%$, a média do percentual de participação é de $16,82 \%$.

Resultado aproximado foi apresentado por Oliveira \& Zocoler (2013), que encontraram média de 18,15\% de participação do custo de irrigação no custo total da produção.

Ao submeter para o índice de Razão Benefício / Custo, a lâminas de 190 mm e $290 \mathrm{~mm}$ proporcionaram maior retorno financeiro e rentabilidade de $5 \%$ proporcionalmente. Neste caso, apesar de a maior lâmina de irrigação (388 mm) ter proporcionado maior produtividade, não foi suficiente para gerar receitas que pudessem cobrir os custos; com isso, sua rentabilidade foi muito baixa. 
Ezekiel (2016) também realizou um estudo sobre análise econômica da produção de milho, porém, foi com agricultores irrigantes no governo do estado de $\mathrm{Oyo}$, na Nigéria, e verificou que houve maior retorno econômico do milho irrigado utilizando irrigação por bomba e shadoof, que são técnicas adotadas pelos agricultores desta região, e que, encontrar o ponto ótimo da irrigação de forma planejada e adequada, pode proporcionar maior renda aos agricultores, pois a demanda de água aplicada influencia na produtividade do milho e na receita de vendas.

De acordo com as lâminas de água, houve acréscimo na aplicação de água de: 35,71\% (lâmina 2 com relação à lâmina 1), 52,63\% (lâmina 3 com relação à 2), e 33,79\% (lâmina 4 com relação à 3). A pesar de a lâmina de 290 mm ter apresentado maior aumento na aplicação da água para irrigação, esta não é a melhor.

A lâmina de $190 \mathrm{~mm}$ apresentou resultado semelhante ao da terceira utilizando menor quantidade de água aplicada, ou seja, com maior economia no uso da água, sendo esta a melhor lâmina a ser utilizada ao relacionar otimização do uso da água com os resultados econômicos (Figura 2).

Concordando com a pesquisa, e diante da preocupação com a crise hídrica em diversos locais, Aziz et al. (2018) desenvolveram um estudo conduzido para avaliar as vantagens de diferentes métodos de irrigação na produtividade da água, como forma de tecnologias de economia de água, e verificou que os métodos de irrigação influenciaram na produtividade e rendimento dos grãos e que o gerenciamento de fertilizantes economizou de $16 \%$ a 21\% de água ao manter outros insumos constantes.

Figura 2. Influência da lâmina de água da irrigação na produtividade e receita líquida do milho safrinha.

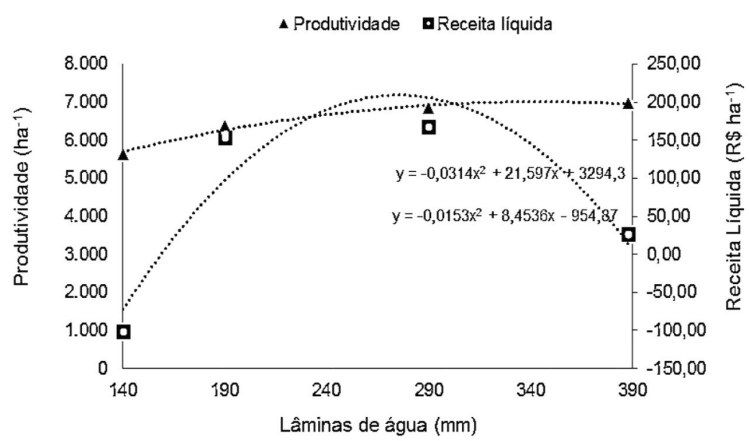

Fonte: Elaborado pela autora.
Com base na análise vertical, as participações dos custos das lâminas de irrigação sobre as receitas cresceram conforme a alta na irrigação: a lâmina de $140 \mathrm{~mm}$ apresentou $10,7 \%$ sobre a receita e a de $388 \mathrm{~mm}$ apontou $24,0 \%$ sobre a receita. Quanto aos custos totais, seus percentuais foram reduzidos em relação à receita de vendas, conforme o aumento da irrigação, devido à compensação no aumento da produtividade. Assim, a participação da receita líquida sobre a receita de vendas cresceu conforme a elevação da irrigação.

Relacionando o resultado da receita líquida das lâminas de água desta pesquisa com a de Martins et al. (2016), em ambas as situações as lâminas que proporcionaram mais retorno financeiro foram as maiores.

Pegorare et al. (2009) também encontrou aumento nos incrementos produtivos com as maiores lâminas, mas esta não gerou maior a renda, devido ao aumento considerável com custo de energia elétrica para aplicação da lâmina, visto que a região onde foi realizado o experimento possui uma tarifa de cobrança de energia elétrica superior à de Tangará da Serra (MT), tornando a maior lâmina inviável economicamente.

A irrigação por pivô central é um dos sistemas que apresentam maior taxa de eficiência na aplicação e no uso da água, sendo que, nesta pesquisa, apresentou $82 \%$ de uniformidade no manejo e, assim como está crescendo a utilização deste tipo de sistema de irrigação no estado de Mato Grosso, seu emprego também aumentou ainda mais em algumas áreas dos EUA. No Kansas, por exemplo, em 2012 a utilização de irrigação por aspersão em sistema de pivô central abrange cerca de $93 \%$ de toda área irrigada (Rogers, 2016). Além disso, a irrigação responde por cerca de um terço de toda retirada de água nos EUA (Maupin et al., 2014), demonstrando seu crescimento no mercado pela eficiência no uso da água.

A eficiência do uso da água do milho safrinha foi reduzida ao aumentar o volume da água, assim, a lâmina de $140 \mathrm{~mm}$ proporcionou maior eficiência, ou seja, para cada $\mathrm{mm}^{-1}$ aplicado de água obteve-se $15,67 \mathrm{~kg}$ de milho, e a lâmina de $388 \mathrm{~mm}$ apresentou redução de $26,80 \%$ da eficiência (Tabela 6).

A lâmina de $190 \mathrm{~mm}$ apresentou a segunda melhor eficiência, economia em uso e custos com irrigação, aliados também a maior retorno econômico. Esta é a melhor lâmina a ser aplicada pelo produtor, visando equilíbrio econômico e ambiental, de acordo com o 
indicador de quantificação da pegada hídrica para o consumo da água (Silva et al., 2013).

O trabalho de Usak (2017) também revela que, conforme avaliações do índice de estresse da água da planta para linhas de milho irrigado, o rendimento dos grãos das diversas variedades do cereal pode ser influenciado pela eficiência do uso da água realizado pelos sistemas de irrigação. A gestão da água é a questão mais importante em áreas com déficit hídrico, já que a agricultura consome a maior parte da água doce em todo o mundo.

A lâmina de $290 \mathrm{~mm}$ proporcionou maior receita líquida, porém, gerou apenas 9,7\% de aumento com relação à lâmina de $190 \mathrm{~mm}$, sendo que esta proporcionou maior aumento, em torno de 250,4\% em relação à primeira (Tabela 7).

Para uma área de 120 há, a lâmina de 140 mm gerou prejuízo de $\mathrm{R} \$ 12.240,60$ pelo fato de a receita não ter sido capaz de pagar os custos totais, devido à baixa produtividade e aos altos custos.

Na cultura do feijão, o consumo de energia elétrica por hectare ocorreu da seguinte maneira: lâmina $295 \mathrm{~mm}=981,3 \mathrm{~kW}$; lâmina 408,65 mm: 1358,8 kW; lâmina 522,17 mm: 1736,3 kW; lâmina 635,69 mm: 2113,8 kW.

Dados aproximados ao consumo da lâmina de $635,69 \mathrm{~mm}$ foram encontrados por Turco et al. (2009) no consumo de energia elétrica máxima de 2.679,16 kW h-1, utilizando pivô central e manejo de tanque classe A.
O menor tempo utilizado para efetuar a operação de irrigação do feijão em 120 ha foi realizado pela lâmina de $295,14 \mathrm{~mm}$, com 639,99 horas, e o maior tempo foi realizado pela lâmina de $635,69 \mathrm{~mm}$, com $1.378,54$ horas, sendo que, dentre as lâminas de água, o aumento foi constante, ou seja, 246 horas a mais entre cada uma delas (Tabela 8).

Na irrigação do feijoeiro, Oliveira \& Zocoler (2013) aplicaram uma lâmina de 251 mm numa área de 103,28 ha, e utilizaram um total de 958 horas em todo o ciclo da cultura para irrigar, resultado superior ao encontrado nesta pesquisa, considerando que, na pesquisa dos autores, a área irrigada foi menor e aplicaram menor quantidade de água.

Em relação aos custos com consumo da energia elétrica por hectare do feijão, a lâmina de 295,14 mm apresentou menor custo, com $\mathrm{R} \$ 467,84$, porém, a lâmina de $635,69 \mathrm{~mm}$ apontou aumento de $115,4 \%$ nos custos em relação à primeira lâmina.

Turco et al. (2009) encontraram resultados aproximados com o custo de energia elétrica do feijoeiro, com R\$ 576,15 no sistema tarifário do grupo B.

Assim, quanto à energia elétrica, a lâmina de 522,17 mm apresentou o maior custo com captação de água para irrigação do feijão, pois consumiu maior quantidade de água, um custo em torno de 115,39\% maior que a lâmina 1;55,55\% maior que a lâmina 2; e 21,74\% maior que a lâmina 3. Nesta situação, o custo

Tabela 6. Produtividade média por hectare e eficiência no uso da água em do milho $\mathrm{kg} \mathrm{mm¹}$

\begin{tabular}{|c|c|c|c|c|}
\hline Lâminas de água (mm) & 140 & 190 & 290 & 388 \\
\hline Produtividade kg ha-1 & 5.642 & 6.380 & 6.842 & 6.975 \\
\hline Lâminas de água + precipitação em $\mathrm{mm}^{-1}$ & 360 & 410 & 510 & 608 \\
\hline Eficiência no uso da água $\mathrm{kg} \mathrm{mm}^{-1}$ & 15,67 & 15,56 & 13,41 & 11,47 \\
\hline
\end{tabular}

Fonte: Elaborado pela autora.

Tabela 7. Receita líquida e índice de rentabilidade razão benefício/custo do milho

\begin{tabular}{lcccc}
\hline \multicolumn{1}{c}{ Lâminas de irrigação } & $\mathbf{1 4 0} \mathbf{~ m m ~}$ & $\mathbf{1 9 0} \mathbf{~ m m}$ & $\mathbf{2 9 0} \mathbf{~ m m}$ & $\mathbf{3 8 8} \mathbf{~ m m}$ \\
\hline Produtividade (kg) & \multicolumn{1}{c}{677.040} & 765.600 & 821.040 & 837.000 \\
Sacas de 60 kg & 11.284 & 12.760 & 13.684 & 13.950 \\
Total Receitas (R\$) & $331.185,40$ & $374.506,00$ & $401.625,40$ & $409.432,50$ \\
Custos de produção (R\$) & $307.959,60$ & $307.959,60$ & $307.959,60$ & $307.959,60$ \\
Custo lâmina de água (R\$) & $35.466,40$ & $48.132,97$ & $73.466,11$ & $98.292,58$ \\
Total dos custos (R\$) & $343.426,00$ & $356.092,57$ & $381.425,71$ & $406.252,18$ \\
Receita líquida (R\$) & $-12.240,60$ & $18.413,43$ & $20.199,69$ & $3.180,32$ \\
RAZÃo B/C (\%) & $\mathbf{0 , 9 6}$ & $\mathbf{1 , 0 5}$ & $\mathbf{1 , 0 5}$ & $\mathbf{1 , 0 1}$ \\
\hline
\end{tabular}

Fonte: Elaborado pela autora. 
de água também aumentou conforme a expansão do volume de água de cada lâmina.

Na cultura do feijão, o aumento do volume de água aplicado ocasionou o aumento na produtividade: lâmina $1=588,14 \mathrm{~kg} \mathrm{ha}^{-1}$; lâmina $2=1.556,11 \mathrm{~kg} \mathrm{ha}^{-1}$; lâmina $3=2.246,30 \mathrm{~kg} \mathrm{ha}^{-1}$; lâmina $4=2.377,68 \mathrm{~kg} \mathrm{ha}^{-1}$.

Corroborando com Cunha et al. (2013) no manejo da irrigação do feijoeiro, o volume de água também influenciou positivamente na produtividade com a aplicação das lâminas.

Uma pesquisa realizada por Mdemu et al. (2017) evidenciou que as questões de fornecimento de água na região Kiwere e Magozi, na Tanzânia, estão influenciando negativamente a produtividade e a rentabilidade dos sistemas de irrigação, sendo que a irrigação provou ser rentável quando a demanda por água aumenta.
A maior taxa de crescimento dos custos foi gerada pela lâmina de 408,65 mm, de 38,5\%, com relação à primeira lâmina. Já a taxa de crescimento dos custos totais (produção + irrigação) foram reduzidos em relação à receita de vendas de 211,3\% na primeira lâmina para 59,3\% na última, consonante ao aumento da irrigação, devido à compensação de crescimento na produtividade. Desta forma, a receita líquida sobre a receita de vendas se elevou consideravelmente conforme o aumento do volume de água (Tabela 9).

A receita líquida da lâmina de 295,14 mm apresentou saldo negativo, pois as receitas não foram suficientes para cobrir os custos totais, tornando-a inviável economicamente. A maior receita foi gerada pela de $635,69 \mathrm{~mm}$, com total de $\mathrm{R} \$ 3.161,72$ por hectare.

De acordo com o índice de rentabilidade Benefício/Custo, a lâmina de $635,69 \mathrm{~mm}$ proporcionou maior produtividade

Tabela 8. Custo da energia elétrica para irrigação do feijão

\begin{tabular}{|c|c|c|c|c|}
\hline Lâminas aplicadas (mm) & 295,14 & 408,65 & 522,17 & 635,69 \\
\hline Lâmina média diária & 7,00 & 7,00 & 7,00 & 7,00 \\
\hline Dias de irrigação & 42 & 58 & 75 & 91 \\
\hline Horas diárias irrigação & 15,18 & 15,18 & 15,18 & 15,18 \\
\hline Horas totais & 639,99 & 886,19 & $1.132,36$ & $1.378,54$ \\
\hline Potência motor kW (250 cv) & 184,00 & 184,00 & 184,00 & 184,00 \\
\hline Consumo de energia total $(\mathrm{kW})$ & $117.758,14$ & $163.058,36$ & $208.354,78$ & $253.651,21$ \\
\hline Preço kW h-1 (R\$) & 0,36 & 0,36 & 0,36 & 0,36 \\
\hline Valor total (R\$) & $42.392,93$ & $58.701,01$ & $75.007,72$ & $91.314,43$ \\
\hline Impostos $(32,43 \%)$ & $13.748,03$ & $19.036,74$ & $24.325,00$ & $29.613,27$ \\
\hline Custo total em 120ha (R\$) & $56.140,96$ & $77.737,74$ & $99.332,73$ & $120.927,71$ \\
\hline Custo da energia (ha) & 467,84 & 647,81 & 827,77 & $1.007,73$ \\
\hline
\end{tabular}

Fonte: Elaborado pela autora.

Tabela 9. Índice de rentabilidade razão benefício / custo e análise vertical (AV) e horizontal (AH) da irrigação do feijão por hectare

\begin{tabular}{lccccccccccc}
\hline \multicolumn{1}{c}{ L } & $\mathbf{2 9 5 , 1 4} \mathbf{~ m m}$ & AV (\%) & $\mathbf{4 0 8 , 6 5} \mathbf{~ m m}$ & AV (\%) & AH (\%) & $\mathbf{5 2 2 , 1 7} \mathbf{~ m m}$ & AV (\%) & AH (\%) & $\mathbf{6 3 5 , 6 9} \mathbf{~ m m}$ & AV (\%) & AH (\%) \\
\hline P & 588 & & 1.556 & & 164,6 & 2.246 & & 44,4 & 2.378 & 5,8 \\
SC & 9,8 & & 26 & & 164,6 & 37 & & 44,4 & 40 & 5,8 \\
RT & $1.921,26$ & 100,0 & $5.083,29$ & 100,0 & 164,6 & $7.337,91$ & 100,0 & 44,4 & $7.767,09$ & 100,0 & 5,8 \\
CP & $3.586,51$ & 186,7 & $3.586,51$ & 70,6 & 0,0 & $3.586,51$ & 48,9 & 0,0 & $3.586,51$ & 46,2 & 0,0 \\
CLA & 473,01 & 24,6 & 654,97 & 12,9 & 38,5 & 836,91 & 11,4 & 27,8 & $1.018,86$ & 13,1 & 21,7 \\
CT & $4.059,52$ & 211,3 & $4.241,48$ & 83,4 & 4,5 & $4.423,42$ & 60,3 & 4,3 & $4.605,37$ & 59,3 & 4,1 \\
RL & $-2.138,26$ & $-111,3$ & 841,82 & 16,6 & 139,4 & $2.914,49$ & 39,7 & 246,2 & $3.161,72$ & 40,7 & 8,5 \\
B/C & $\mathbf{0 , 4 7}$ & & $\mathbf{1 , 2 0}$ & & & $\mathbf{1 , 6 6}$ & & & $\mathbf{1 , 6 9}$ & \\
\hline
\end{tabular}

${ }^{*}$ L: lâmina; P: produtividade $\left(\mathrm{kg} \mathrm{ha}^{-1}\right)$; $\mathrm{SC}$ : sacas de $60 \mathrm{~kg}$; RT: receita total $\left(\mathrm{R} \$ \mathrm{ha}^{-1}\right)$; $\mathrm{CP}$ : custo de produção $\left(\mathrm{R} \$\right.$ ha $\left.\mathrm{a}^{-1}\right)$; CLA: custo de lâmina de irrigação $\left(\mathrm{R} \$\right.$ ha $\left.^{-1}\right)$; $\mathrm{CT}$ : custo total $\left(\mathrm{R} \$ \mathrm{ha}^{-1}\right)$; RL: receita líquida $\left(\mathrm{R} \$ \mathrm{ha}^{-1}\right)$; $\mathrm{B} / \mathrm{C}$ : benefício/custo (\%). Fonte: Elaborado pela autora. 
Tabela 10. Receita líquida e índice de rentabilidade razão benefício/custo do feijão

\begin{tabular}{|c|c|c|c|c|}
\hline Lâminas de irrigação & $295,14 \mathrm{~mm}$ & $408,65 \mathrm{~mm}$ & $522,17 \mathrm{~mm}$ & $635,69 \mathrm{~mm}$ \\
\hline Produtividade $(\mathrm{kg})$ & 70.577 & 186.733 & 269.556 & 285.322 \\
\hline Sacas de $60 \mathrm{~kg}$ & 1.176 & 3.112 & 4.493 & 4.755 \\
\hline Total Receitas (R\$) & $230.550,88$ & $609.995,12$ & $880.549,60$ & $932.050,56$ \\
\hline Custos de produção (R\$) & $430.381,20$ & $430.381,20$ & $430.381,20$ & $430.381,20$ \\
\hline Custo lâmina de água (R\$) & $56.760,75$ & $78.595,91$ & $100.429,28$ & $122.262,65$ \\
\hline Total dos custos (R\$) & $487.141,95$ & $508.977,11$ & $530.810,48$ & $552.643,85$ \\
\hline Receita líquida (R\$) & $-256.591,07$ & $101.018,01$ & $349.739,12$ & $379.406,71$ \\
\hline RAZÃO B/C (\%) & 0,47 & 1,20 & 1,66 & 1,69 \\
\hline
\end{tabular}

Fonte: Elaborado pela autora.

Tabela 11. Produtividade média por hectare e eficiência no uso da água em $\mathrm{kg} \mathrm{mm}^{-1}$ do feijão

\begin{tabular}{lrrrr}
\hline \multicolumn{1}{c}{ Lâminas de água } & \multicolumn{1}{c}{ L1 } & \multicolumn{1}{c}{ L2 } & L3 & L4 \\
\hline${\text { Produtividade } \mathrm{kg} \mathrm{ha}^{-1}}^{5}$ & 588,14 & $1.556,11$ & $2.246,30$ & $2.377,68$ \\
Lâminas de água em mm & 295,14 & 408,65 & 522,17 & 635,69 \\
Eficiência no uso da água $\mathbf{~ k g ~ m m}^{-1}$ & $\mathbf{1 , 9 9}$ & $\mathbf{3 , 8 1}$ & $\mathbf{4 , 3 0}$ & $\mathbf{3 , 7 4}$ \\
\hline
\end{tabular}

Fonte: Elaborado pela autora.

e retorno financeiro, visto que cada unidade monetária gasta resultou em aumento de $69 \%$ de renda líquida em relação ao custo total. Porém, apresentou apenas 8,5\% de aumento com relação à lâmina de 522,17 mm.

Comparada às demais, a lâmina de 522,17 mm apresentou maior taxa de crescimento da receita líquida, com $246,2 \%$, sendo esta a melhor lâmina em termos econômicos (Figura 3).

Para uma área de 120 hectares, a menor lâmina, de 295,14 mm, apresentou prejuízo de $\mathrm{R} \$ 256.591,07$ na receita líquida. A maior receita foi gerada pela lâmina de $635,69 \mathrm{~mm}$, com taxa de $69 \%$ de retorno econômico (Tabela 10).

Um modelo matemático setorial foi formulado por Alabdulkader et al. (2012) para otimizar o padrão de cultivo na Arábia Saudita, visando maximizar o retorno líquido anual do setor agrícola na Arábia Saudita e assegurar a alocação eficiente dos escassos recursos hídricos e terras aráveis entre as culturas concorrentes. Os resultados mostraram o potencial da Arábia Saudita para otimizar seu padrão de cultivo e gerar um retorno líquido estimado equivalente a US\$ 2,42 bilhões por ano. O padrão de cultivo otimizado na Arábia Saudita foi associado a uma economia de cerca de 53\% no uso da água.

Em relação ao uso da água no feijão, a maior eficiência foi obtida pela lâmina de 522,17 mm com 4,30 kg mm-1 .
Figura 3. Influência da lâmina de água da irrigação na produtividade e receita líquida do feijão

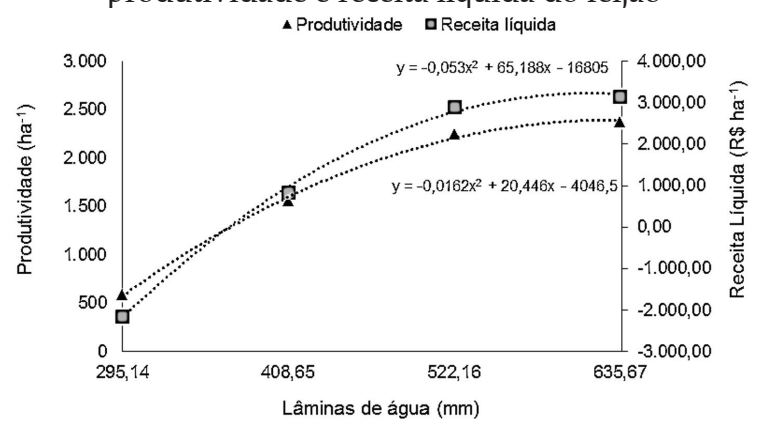

Fonte: Elaborado pela autora.

A lâmina de 295,14 mm proporcionou maior economia no consumo da água dos processos produtivos, porém, não apresentou melhor eficiência do uso da água (Tabela 11).

A eficiência do uso da água no feijoeiro foi de: 9,22 kg ha-1; 8,64 kg ha-1; 8,72 kg ha-1; 8,86 kg ha-1, respectivamente. Esses resultados foram superiores aos encontrados nesta pesquisa. Houve mais eficiência no uso da água por ter proporcionado maior produtividade com menor quantidade de água (Cunha et al., 2013).

Para a cultura do feijão, a lâmina de 522,17 mm é a indicada para irrigação considerando a economia do recurso hídrico, bem como a economia em relação aos custos das lâminas e maior retorno econômico, visando equilíbrio ambiental e financeiro, pois apresentou a maior eficiência no uso da água e maior taxa de rentabilidade, 
de acordo com quantificação da pegada hídrica para o consumo da água (Silva et al., 2013).

A baixa eficiência do uso da água no feijão ocorreu em razão da maior necessidade de irrigação, visto que não houve precipitação na época da semeadura e desenvolvimento da planta, entre 11/07/2014 e 30/09/2014, um dos períodos menos chuvosos do ano em Mato Grosso.

\section{Conclusão}

A análise da rentabilidade das lâminas de água e a quantificação do consumo hídrico permitiu estabelecer o manejo adequado da irrigação, com planejamento para otimização da água que contribui para economia e melhor uso na cadeia produtiva.

Em relação ao custo variável do manejo das lâminas, para a cultura do milho, por hectare obteve-se: $140 \mathrm{~mm}=\mathrm{R} \$ 295,55 ; 190 \mathrm{~mm}=\mathrm{R} \$ 401,11 ; 290 \mathrm{~mm}=\mathrm{R} \$ 612,22 ;$ $388 \mathrm{~mm}=\mathrm{R} \$ 819,10$. Já para a cultura do feijão, os custos das lâminas foram: 295,14 mm $=\mathrm{R} \$ 473,01$; $408,65 \mathrm{~mm}=\mathrm{R} \$ 654,97 ; 522,17 \mathrm{~mm}=\mathrm{R} \$ 836,91$; e $635,69 \mathrm{~mm}=\mathrm{R} \$ 1.018,86$.

A lâmina de $190 \mathrm{~mm}$ para a irrigação do milho e de 522,17 mm para a irrigação do feijão são as melhores a serem aplicadas pelo produtor, visando equilíbrio econômico e ambiental, pois apresentaram maior eficiência no uso da água aliados à maior taxa de rentabilidade frente às demais lâminas.

\section{Agradecimentos}

À Universidade do Estado de Mato Grosso (Unemat), ao grupo de pesquisa do Laboratório de Meteorologia e à Coordenação de Aperfeiçoamento de Pessoal de Nível Superior (Capes) pelo apoio financeiro à pesquisa.

\section{Referências}

Agência Nacional de Águas - ANA. (2016). Levantamento da Agricultura Irrigada por Pivôs Centrais no Brasil - 2014 relatório síntese (33 p.). Brasília: Agência Nacional de Águas.
Alabdulkader, A. M., Al-Amoud, A. I. \& Awad, F. S. (2012). Optimization of the cropping pattern in Saudi Arabia using a mathematical programming sector model. Agricultural Economics, 58(2), 56-60. Recuperado em 23 de junho de 2018, de https: / / www.agriculturejournals. cz/publicFiles/59671.pdf

Aziz, O., Bin, L., Imtiaz, M., Chen, J., He, Y., Lin, L., Ali, S., Riaz, M., Mehmood, S., Rizwan, M. \& Lu, G. (2018). Irrigation methods affect water productivity, grain yield, and growth responses of rice at different levels of nitrogen. Journal of Soil and Water Conservation. 73(3), 329-336. Recuperado em 15 de junho de 2018, de http:/ / www.jswconline.org/content/73/3/329.abstract

Barros, F. G. N., \& Amim, M. M. (2008). Água: um bem econômico de valor para o Brasil e o mundo. Revista Brasileira de Gestão e Desenvolvimento Regional. 4(1), 75-108.

Beyruth, Z. (2008). Água, agricultura e as alterações climáticas globais. Revista Tecnologia \& Inovação Agropecuária. 1(1). Recuperado em 18 de março de 2017, de http:/ / www.apta.sp.gov.br/Publicacoes/T\&IA/T\&IAv1n1/ Revista_Apta_Artigo_Agua_Agricultura.pdf

Castiblanco, C. J. M. (2009). Economia de energia em irrigação por pivô central em função de melhoria na uniformidade da distribuição da água (Dissertação de mestrado). Escola Superior de Agricultura "Luiz de Queiroz", Piracicaba. 70 p. Recuperado em 13 de outubro de 2015, de www. teses.usp.br/teses / disponiveis / 11/ ...22062009.../ Christian_Mendoza.pdf

Castro Júnior, W. L., Oliveira, R. A., Silveira, S. F. R., \& Andrade Junior, A. S. (2015). Viabilidade econômica de tecnologias de manejo da irrigação na produção do feijão-caupi, na região dos Cocais-MA. Revista Engenharia Agrícola, 35, 406-418. Recuperado em 03 de setembro de 2015, de http:www.scielo.br/pdf/eagri/v35n3/18094430-eagri-35-3-0406.pdf.

Centro de Estudos Avançados em Economia Aplicada - CEPEA. (2013). Relatório da safra 2012/13: Grãos - Cruz Alta/RS (84 p.). Piracicaba: Universidade de São Paulo, Escola Superior de Agricultura "Luiz De Queiroz" ESALQ, Departamento de Economia, Administração e Sociologia.

Companhia Nacional do Abastecimento - CONAB. (2017) Boletim da safra de grãos. Recuperado em 24 de outubro de 2019, de https: / / www.conab.gov.br/info-agro/safras / graos/boletim-da-safra-de-graos?start $=30$

Costa, M. B. (2006). Avaliação da irrigação por pivô central na cultura do café (Conffea canefhora L.) e na cultura do mamoeiro (Carica papaya L.) no município de Pinheiros ES (Tese de doutorado). Universidade de São Paulo: Piracicaba. 88 p. Recuperado em 23 de setembro de 2015, de www.teses.usp.br/teses/disponiveis/11/11143/ tde-10052006-142044/.

Cunha, P. C. R., Silveira, P. M., Nascimento, J. L., \& Alves Junior, J. (2013). Manejo da irrigação no feijoeiro cultivado 
em plantio direto. Revista Brasileira de Engenharia Agrícola e Ambiental. 17(7), 735-742. Recuperado em 07 de janeiro de 2017, de http:/ / www.scielo.br/pdf/rbeaa/v17n7/ a07v17n7.pdf.

Ezekiel, A. A. (2016). Economic Analysis of Maize Production Among Irrigation Farmers in Orire Local Government Area, Oyo State, Nigeria. Sociology Study, 6(3), 186-195.

Fenner, W. (2015). Otimização dos recursos hídricos aplicados à cultura do feijoeiro no estado de Mato Grosso - Brasil (Dissertação). Universidade do Estado de Mato Grosso, Tangará da Serra.

Frizzone, J. A. (2007). Planejamento da irrigação com uso de técnicas de otimização. Revista Brasileira de Agricultura Irrigada, 1(1), 24-49.

Gomes, A. M., Bittar, O. J. N V., \& Fernandes, A. D. (2016). Sustentabilidade na Saúde: água e seu consumo. Revista de Gestão em Sistemas de Saúde. 5(1), 76-85.

Instituto Mato-Grossense de Economia AgropecuáriaIMEA. (2016). Custo da produção de milho. Recuperado em 21 de outubro de 2019, de http:/ / www.imea.com.br / imea-site $/$ relatorios-mercado-detalhe $? \mathrm{c}=3 \& \mathrm{~s}=3$

Köpp, L. M., Peiter, M. X., Ben, L. H. B., Nogueira, H. M. C. M., Padron, R. A. R., Robaina, A. D, \& Busk, T. C. (2015). Simulação da necessidade hídrica e estimativa de produtividade para cultura do milho em municípios do RS. Revista Brasileira de Milho e Sorgo, 14(2), 235-246.

Lotidi, P. A., \& Mavropoulos, T. I. (2018). New methods for the calculation of the probability of operation of each outlet in on-demand irrigation networks. Agricultural Water Management, 206, 252-264. Recuperado em 22 de junho de 2018, de https:/ / www.sciencedirect.com/science/article/ pii/S0378377418303937?showall\%3Dtrue\%26via\%3Dihub

Martins, J. D., Petry, M. T., Rodrigues, G. C., \& Carlesso, R. (2016). Viabilidade econômica da irrigação deficitária em milho irrigado por gotejamento. Irriga, 1(1), 150-165.

Maupin, M. A., Kenny, J. F., Hutson, S. S., Lovelace, J. K., Barber, N. L., \& Linsey, K. S. (2014). Estimated use of water in the United States in 2010 (56 p.). U.S. Geological Survey. Recuperado em 16 de junho de 2018, de http: / / pubs.usgs.gov/circ/1405/.

Mdemu, M. V., Mziray, N., Bjornlund, H., \& Kashaigili, J. L. (2017). Barriers to and opportunities for improving productivity and profitability of the Kiwere and Magozi irrigation schemes in Tanzania. International Journal of Water Resources Development. 33(5), 725-739. Recuperado em 18 de junho de 2018, de https: / / www.tandfonline.com/ doi/ pdf/10.1080/07900627.2016.1188267? needAccess=true.

Oliveira, A. S., Pereira, F. A. C., Paz, V. P. S., \& Santos, C. A. (2004). Avaliação do desempenho de sistemas pivô central na região oeste da Bahia. Irriga, 9(2), 126-135.
Oliveira, J. S., \& Zocoler, J. L. (2013). Custos da irrigação e receita líquida do feijoeiro em um sistema pivô central sob variação do comprimento da tubulação de recalque e desnível topográfico. Engenharia Agrícola, 33(1), 121-128.

Pegorare, A. B, Fedatto, E, Pereira, S., Souza, L. C. F, \& Fietz, C. R. (2009). Irrigação suplementar no ciclo do milho "safrinha" sob plantio direto. Revista Brasileira de Engenharia Agrícola e Ambiental, 13(3), 262-271.

Rogers, D. H. (2016, february 23-24). Performance of center pivot irrigation systems. In Proceedings of the 28th Annual Central Plains Irrigation Conference. Thompson, Kansas: CPIA. Recuperado em 11 de junho de 2018, de https: / / www.ksre.k-state.edu/irrigate/ reports / Rogers16.pdf.

Ruviaro, C., Dorneles, J. G., Silva, A. M., \& Bem, C. A. V. (2011). Comportamento da soja submetida a diferentes regimes hídricos e viabilidade da irrigação suplementar na região do vale do Jaguari-RS. Perspectiva, 35(131), 79-90.

Silva, V. P. R., Aleixo, D. O., Dantas Neto, J., Maracajá, K. F. B., Araújo, L. E., \& Vicente P. R. (2013). Uma medida de sustentabilidade ambiental: Pegada hídrica. Revista Brasileira de Engenharia Agrícola e Ambiental, 17(1), 100105. Recuperado em 25 de julho de 2017, de http:/ / www.agriambi.com.br

Soares F. C., Peiter, M. X., Diasrobaina, A., Vivan, G. A, \& Parizi, A. R. C. (2012). Resposta da cultura do milho à variabilidade hídrica em solo sob pivô central. Irriga, 17(2), 220-233.

Thakur, A. K., Mandal, K. G., Mohanty, R. K., \& Ambast, S. K. (2018). Rice root growth, photosynthesis, yield and water productivity improvements through modifying cultivation practices and water management. Agricultural Water Management, 206, 67-77. Recuperado em 18 de junho de 2018, de https:/ / www.sciencedirect.com/ science/article/pii / S0378377418304232

Turco, J. E. P., Rizzatti, G. S., \& Pavani, L. C. (2009). Custo de energia elétrica em cultura do feijoeiro irrigado por pivô central, afetado pelo manejo da irrigação e sistemas de cultivo. Engenharia Agrícola, 29(2), 311-320.

Usak, A. B. (2017). Identification of water usage efficiency for corn (Zea mays L.) lines irrigated with drip irrigation under green house conditions asPer plant water stress index evaluations. Turkish Journal of Agricultural Research, 4(1), 1-9. Recuperado em 16 de junho de 2018, de http: / / dergipark.gov.tr/download/article-file/ 286695

Vescove, H. V. (2010). Consumo e custo de energia elétrica na cultura de citros irrigada por gotejamento e microaspersão, com três lâminas de água. Irriga, 15(1), 75-89.

Victorino, C. J. A. (2007). Planeta água morrendo de sede: uma visão analítica na metodologia do uso e abuso dos recursos hídricos. Porto Alegre: EDIPUCRS. 231 p. 